\title{
Risk factors analysis and risk assessment of sudden pollution from traffic accidents in the Middle Route of South-to-North Water Diversion Project
}

\author{
Ming Tang ${ }^{1, a^{*}}$, Jin Quan ${ }^{1, b,}$, Xiaohui Lei ${ }^{1}$, Hezheng Zheng ${ }^{2}$ and Tao Tang ${ }^{3}$ \\ ${ }^{1}$ China Institute of Water Resources and Hydropower Research, Beijing 100038 , China \\ ${ }^{2}$ Changjiang Survey, Planning, Design and Research Co., Ltd. Wuhan 430051; China \\ ${ }^{3}$ Construction and Administration Bureau of South -to -North Water Diversion Middle route Project, Beijing 100038, China
}

\begin{abstract}
The traffic bridges along the route of South-to-North Water Diversion Project are numerous. Once a traffic accident occurs causing pollutants in the channel, the water safety, ecological environment and economic development of water receiving areas along the line will be affected .We investigate the bridges along the channel, focusing on the investigation and analysis of hazardous chemicals, nearby backwater gates and water inlets involving 173 cross-channel bridges with large traffic volume. The risk evaluation index system of sudden water pollution is established in this study, while the risk of different bridges is evaluated. We divide bridges in three risk grades, and delimit key prevention areas and key monitoring objects. And the stress of traffic risk factors on the water quality safety is summarized. It is significant for being regarded as basis for contingency plans, hierarchical responses and emergency material reserve for the middle line of the south-to-north water diversion project.
\end{abstract}

\section{Introduction}

The south-to-north water diversion project is the largest inter-basin water diversion project in the world. It is a significant strategic infrastructure to alleviate water shortages in northern China, achieve rational allocation of water resources, ensure sustainable economic and social development, and build an overall well-off society. The middle route project is the lifeline connecting the Danjiangkou reservoir with the four provinces of Beijing, Tianjin, Hebei and Henan, of which the average annual water transferred is 9.5 billion $\mathrm{m}^{3}$, and the beneficiary population has reached 53.1 million. It is responsible for more than $70 \%$ of urban water supply in Beijing, and the proportion of water supply in the water area is growing. The water supply target of the Middle Route of the south-to-north water diversion project is mainly urban domestic and industrial water along the line, and the water supply network covers 97 outlets and 293 water plants with the high requirements for water quality.

The main canal adopts one-way single-line water transportation, with the water transportation distance of 1,432 kilometers. The cross buildings and control buildings along the road are dense, and the factors affecting water quality are complex.

There are about 1,238 cross-canal bridges along the main canal of the middle line, which has become an important risk point for vehicles to transport chemicals and throw into the canal. Since the water flowed on December 12, 2014, cross-canal bridge traffic accidents

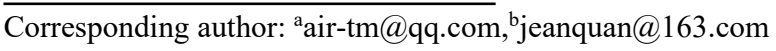

have occurred occasionally. Although there is no direct impact on the quality of the diverted water conveyance, the threat of sudden water pollution from traffic accidents has emerged and attracted attention. Therefore, for the purposes to make water pollution emergency strategy, take good measures to prevent water pollution and plan emergency material reserve layout, the sudden pollution risk factors of traffic accidents are investigated and analyzed. And it is necessary and urgent to put forward a set of index system to evaluate the risk of sudden pollution from traffic accidents in middle line. There are many risk assessments of traffic accidents and sudden water pollution in rivers at home and abroad, but less risk assessment on sudden water pollution from traffic accidents in the main canal of south-to-north water diversion middle route. Li Jiahui, Guo Liang ${ }^{[20]}$, centered on the Hongze Lake in the south-to-north water diversion project, investigated the pollution source information of 22 factories in the surrounding cities, established an index system for river basin hazard source identification and evaluation, and conducted risk calculation. According to the analysis results of the main risk sources in the main canal of middle line, Shi Yueying ${ }^{[1]}$ considered that the occurrence of traffic accidents risk was more probable than that of other risk sources, with weak controllability of risks, and performed spatial clustering analysis of risk sources for traffic accident risk.

Wang Huadong and Wang $\mathrm{Fei}^{[3]}$ carried out environmental risk assessment on middle line water 
source of the south-to-north water diversion project, performed risk identification by analytic hierarchy process, estimated the risk probability by the fuzzy probability-- accident tree analysis method, estimated the risk consequences using the statistical analysis method and the analogy analysis method, and comprehensively evaluated the risk by gray correlation analysis method and comprehensive index method, making the conclusion that the main environmental risk accidents of the engineering and environmental composite system were dam breaks, and the extraordinary floods and destructive earthquakes were the main causes. Tian Weimin ${ }^{[2]}$ analyzed the actual flood control safety situation of Beijing-Guangzhou Railway cross-buildings, compared the design indicators of the Beijing-Guangzhou Railway (Hebei Province section) and the main canal (Hebei Province section) and the river crossing buildings, and considered that the risk of water damage undertaken by the crossing buildings of main canal in middle line was quite low.

\section{Methodology}

\subsection{Risk factors analysis}

\subsubsection{Possibility analysis of accident occurrence}

There are various direct causes of accidents, such as vehicle mechanical failure, driver's carelessness or fatigue driving, environmental conditions, vehicle types, lighting conditions, and so on. The possibility estimation of accident occurrence on the bridge can be analyzed from three aspects, the frequency of vehicles passing through, the bridge attribute, and the number of surrounding chemical plants.

(1) The frequency of vehicles passing through bridges

The frequency of vehicles passing through bridges is directly related to the probability of sudden water pollution from traffic accidents. The frequency statistics are counted according to three time periods per day, 9:00-10:00 am, 15:00-16:00 pm, and 12:00 pm to 1:00 am. The arithmetic mean was taken as the frequency of vehicles passing per hour, and then the frequency of vehicles passing per day was obtained.

The frequencies of hazardous chemicals vehicles passing through in three days were ranked: Grade one, the total number of hazardous chemicals vehicles passing through within three days $\geq 50$; Grade two, the total number of hazardous chemicals vehicles passing through within three days $<50$ and $\geq 10$; Grade three, the total number of hazardous chemicals vehicles passing through within three days $<10$.

\section{(2) Bridge attributes}

Most of the bridges surveyed along the route are highway bridges, railway bridges, water bridges (aqueducts), foot bridges and other special bridges. Different types of bridges are divided into three types of risks: Class I risk bridges, highway bridges; Class II risk bridges, railway bridges; Class III risk bridges, foot bridges and other special bridges.

(3) Number of surrounding chemical plants

The number of chemical plants in the range of $10 \mathrm{~km}$ around the bridge is investigated.

\subsubsection{Estimation and analysis of pollution impact degree}

In the cases of sudden water pollution caused by traffic accidents, the types of pollutants are mainly highly toxic chemicals and other chemicals that are harmful to the human body, facilities and the environment. The weight and toxicity of the chemicals carried by vehicles determine the size of the pollution hazard. The distance between the location of the pollution and the downstream water outlet is related to the impact on the water intaking.

(1) Weight of chemicals carried by vehicles

Counting the weight per vehicles carrying chemicals and the design load of the highway bridge during the survey and investigation period, the load per vehicle is averaged 3 tons. According to the frequency level of hazardous chemicals vehicles passing through, the weight of chemicals carried by vehicles are also divided into three grades: Grade one, the total weight of chemicals carried by vehicles within three days $\geq 150$ tons; Grade two, the total weight of chemicals carried by vehicles within three days $>30$ tons; Grade three, the total weight of chemicals carried by vehicles within three days $<30$ tons.

(2) Type and toxicity of chemicals carried by vehicles.

27 types of typical chemicals are surveyed and investigated in this paper. The main chemicals carried by vehicles are divided into 7 categories, the categories and properties are as follows:

1. Benzene species

(1)Main common substances: benzene, toluene, nitrobenzene, 1,2-dinitrobenzene, 1,3-dinitrobenzene, etc.

(2) Chemical characteristics: colorless light yellow transparent oily liquid, strong fragrant smell, volatile to vapor, flammable and toxic. Benzene compounds have been identified as strong carcinogens by the World Health Organization.

\section{Ethers}

(1)Main common substances: methyl ether, ether, ethylene oxide, petroleum ether, methyl ether.

(2)Chemical characteristics: except for methyl ether and ethyl methyl ether which are gas, most ethers are flammable liquids with a special smell and a relative density of less than one. Generally, they are slightly soluble in water and soluble in organic solvents, more stable compound that can form salts with strong acids.

3. Aldehydes and acetals

(1)Main common substances: Formaldehyde, acetaldehyde, acrolein, glyoxal, succinaldehyde, glutaraldehyde, benzaldehyde, etc.

(2)Chemical characteristics: The compound containing an aldehyde group has two major classes of aliphatic aldehydes and aromatic aldehydes. The low molecular aldehydes are gases, while most of the 
aliphatic aldehydes are a liquid, and the high molecular aromatic aldehydes are a high-melting solid. Aldehydes are readily soluble in water, with a stimulating effect. The degree of stimulation decreases as the number of carbon atoms increases, by which the stimulation site also changes.

\section{Alcohols}

(1)Main common substances: Methanol, ethanol, n-butanol, 1-butanol, 2-methyl-1-propanol, etc.

(2) Chemical characteristics: generally, they are a colorless liquid or solid. Alcohols are chemically active, and both the carbon-oxygen bond and the hydrogen-oxygen in the molecule are polar bonds. Hydrogen-oxygen bond cleavage and carbon-oxygen bond cleavage can be carried out with the hydroxyl group as the center. Further, a carbon atom bonded to a hydroxyl group is easily oxidized to form an aldehyde, a ketone or an acid.

5. Petroleum

(1)Main common substances: Petroleum and its refined products, such as kerosene, diesel, gasoline, etc.

(2) Chemical characteristics: Mineral oil chemicals are mixtures of various hydrocarbons. Petroleum can be present in water in dissolved, emulsified and dispersed states. After entering the water environment, petroleum can form an oil film on the water surface, affecting the reoxygenation process of the water body, causing the water body lack of oxygen, endangering the life of aquatic organisms and the aerobic degradation of organic pollutants. The cyclic hydrocarbon chemicals in petroleum have significant biological toxicity.

6. Acids and alkalis

(1)Main common substances: Hydrochloric acid, sulfuric acid, nitric acid, phosphoric acid, hydrofluoric acid, phosphorous acid, hydrobromic acid, etc.

(2)Chemical characteristics: The acid chemically refers to a compound of which the cation generated when ionized in a solution is completely hydrogen ion, and the $\mathrm{pH}$ of their diluted solution is less than 7 .

Alkalis chemically refer to a compound of which the anion generated when ionized in a solution is completely hydroxide ion, and the $\mathrm{pH}$ of their diluted solution is greater than 7 .

\section{Sulfides}

(1)Main common substances: sodium sulfide, potassium sulfide, hydrogen sulfide, barium sulfide, calcium sulfide, etc.

(2) Chemical characteristics: sulfides refer to a class of compounds formed by strong electropositive metals or non-metals and sulfur. Most metal sulfides can be considered as salts of hydrosulfuric acid.

For the toxicity analysis of 27 types of chemicals, the toxicity values $\mathrm{K} 1, \mathrm{~K} 2 \ldots \mathrm{K} 27$ were respectively assigned according to the difficulty of disposal, ranging from 0 to 100. The comprehensive toxicity of the chemicals carried by a car can be calculated by the following formula (1), and the comprehensive toxicity intensity can be calculated according to formula (2):

$$
\begin{gathered}
P_{j}=w_{1} k_{1}+w_{2} k_{2}+\cdots+w_{i} k_{i} \\
i=1,2, \cdots, 27
\end{gathered}
$$

$$
U_{j}=\frac{P_{j}}{P_{\max }} j=1,2, \cdots, 173
$$

where: $W i$ is the weight of the chemicals carried through the bridge in one day; $k i$ is the toxicity value; $i$ is the chemical type; $P j$ is the comprehensive toxicity value of the $j^{\text {th }}$ bridge; $P_{\max }$ is the maximum toxicity value of the 173 bridges; $U j$ is the comprehensive toxicity intensity of the $j^{\text {th }}$ bridge.

(3) Distance of downstream water outlet

Considering the interval time between inspections, the water outlets within 2000 meters from the point of the pollution occurrence are likely to be affected.

\subsubsection{Predictive analysis of pollution disposal effect}

After the accident, an emergency response is needed to ensure the lives and property safety of the people along the line, water supply safety, and engineering safety as the decision-making goals. Under the premise of ensuring the above objectives, the pollution groups will be discharged and disposed of as soon as possible. Therefore, the effect estimation of pollution disposal should be based on factors such as the locations of the effective backwater gates and the accident occurrence, the amount of water discarded, the location of the emergency reserve materials, and the degree of pollution received by the backwater area. The distance from the accident location to the downstream effective backwater gates determines the distance of the pollution group transferred and the scope affected by the accident. Pollutants are diffused and diluted during the transportation process, and the distance of the pollutants transporting affects the amount of discarded water. At the same time, when selecting the effective backwater gates, the location of the emergency reserve materials, the length of the backwater channel and the acceptance degree of pollution in the backwater area should also be considered, as well as considering whether the pollutants discharged into the backwater area in the backwater channel could decrease the pollution of the backwater area.

(1) Distance of effective backwater gates

After the pollution occurs, the pollution may not be discovered in the first time, so the nearest backwater gates from the point of the pollution occurrence may not be opened in time.

In the channel, the emergency materials can be used first to dispose before backwater. Therefore, the pollution occurrence time and response time should be considered in the selection of the effective backwater gates, and the appropriate distance of the backwater gates is selected as an indicator to measure the effect of pollution treatment. The transport distance of the pollutant at the peak concentration and the length of the pollution area can be calculated by the following formula ${ }^{[7]}$.

$$
D=60 v T
$$

where: $D$ is the transport distance of the pollutant at the peak, $\mathrm{m} ; v$ is the average flow rate, $\mathrm{m} / \mathrm{s} ; T$ is the diffusion time, min.

The expression of the length $S$ of the polluted area 
along the channel in the time of $T$ :

$$
\begin{gathered}
S=\int_{0}^{T} v d t=2 a \sqrt{2} D_{L}^{0.5} T^{0.5} \\
v=\frac{m \sigma}{t}=\frac{a \sqrt{\int 2 E_{x} d t}}{t}=a \sqrt{2} D_{L}^{0.5} t^{-0.5} \\
D_{L}=\frac{1}{2} \frac{\partial \sigma^{2}}{\partial t}
\end{gathered}
$$

where: $D_{L}$ is the coefficient of dispersion, $v_{\text {is }}$ the longitudinal stretching speed of the pollutant.

(2) Emergency materials reserve

At present, the sites of emergency materials reserve near the bridges along the line are scarce.

Considering the time interval of pollution discovery and the time of emergency material release, the emergency reserve rooms at $1 \sim 2 \mathrm{~km}$ from the bridge are the best, followed by those at $2 \sim 3 \mathrm{~km}$, and those at $0 \sim 1 \mathrm{~km}$ are the most inferior, so the locations of the emergency material reserve room are divided into three

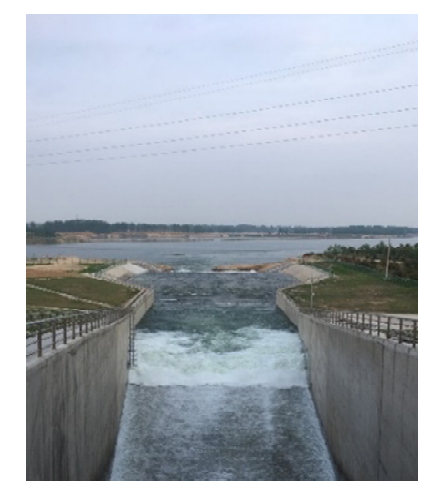

Figure 1.sand river dewatering area

Therefore, according to whether the backwater area can accept pollution and the conditions of the backwater area, the acceptable pollution degree of the backwater area can be divided into four levels: level 1 , pollution cannot be accepted in the backwater area; level 2, the pollution is acceptable after being disposed in the backwater canal; level 3, part of untreated pollution and some of the pollution that has been disposed of in the backwater canal is acceptable; level 4, untreated pollution is acceptable.

\subsection{Evaluation index system}

Comprehensively taking the above risk factors into account, an index system of three-layer stepped structure is drawn up, as shown in Figure 3.

The first layer is the target layer $A$, which grades.

(3) Degree of acceptable pollution in the backwater area.

Considering the situations of the backwater gates and the backwater area, the backwater gates can be directly opened for the acceptable pollutants in the backwater area. Taking the impact on the backwater area into account, pollutants cannot be accepted in some important backwater areas. For example, the Yellow River is responsible for the supply of the downstream water resource. After the upstream pollution occurs, the Yellow River backwater gate cannot open preventing the polluted water from the Yellow River main canal.

According to the length of the backwater canal (Figure 1, Figure 2), three types of pollution disposal methods can be adopted: after being disposed in the backwater canal, it is discharged into the backwater area; some of the polluted water bodies are disposed in the backwater canal, and some are disposed in the backwater area; All are discharged into the backwater area and disposed.

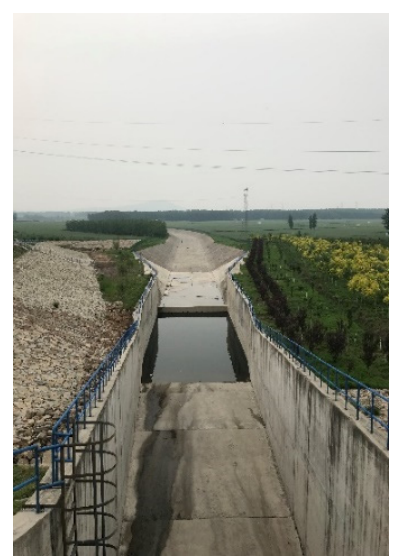

Figure 2. white river dewatering area

comprehensively reflects the assessment index system of water pollution from traffic accident in the middle line of the south-to-north water diversion;

The second layer is the criterion layer $B$, consisting of three subsystems, reflecting the possibility of accident $B 1$, the severity estimation $B 2$ of pollution, and the degree estimation $B 3$ of pollution disposal;

The third one is the index layer $C$, and according to the actual situation of the main canal in the middle line, 9 indicators are selected: the number of surrounding chemical plants $C 1$; the frequency of vehicles passing through $C 2$; the bridge attribute $C 3$; the weight of chemicals carried by vehicles $C 4$; the toxicity of chemicals $C 5$; the distance of the nearest water outlet $C 6$; the distance of the effective backwater gate $C 7$; the emergency material reserve $C 8$; the acceptance of pollution by a backwater gate $C 9$. 


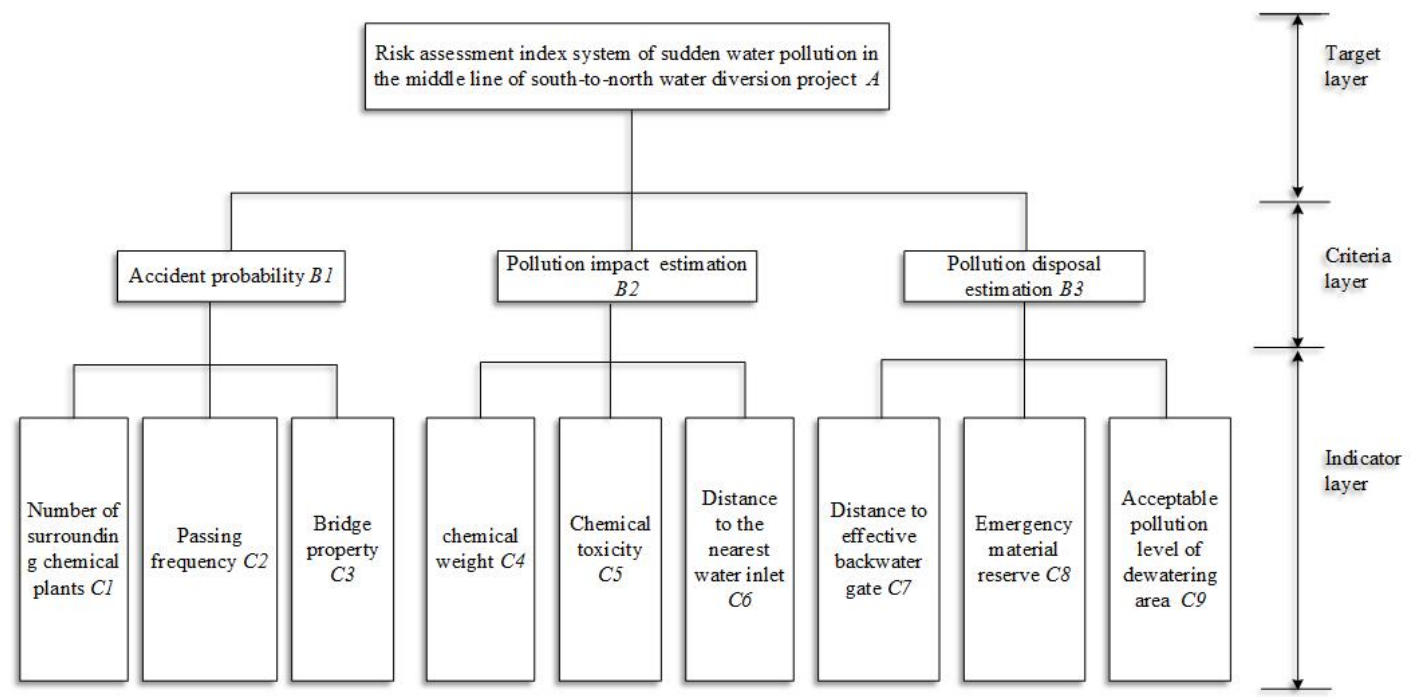

Figure 3. Risk assessment index system of sudden water pollution in the middle line of south-to-north water diversion project

\subsection{Establishment of index weights}

\subsubsection{Judgment matrix}

Since each indicator value belongs to a different type of judgment values, it is necessary to build a judgment matrix to reflect the weight of the factor of the same layer in that of the upper layer. In this paper, the judgment is quantified by the 1-9 scale method, and the importance between indicators in each layer is objectively evaluated, constructing the judgment matrix $\mathrm{R}$ according to the scale obtained from the evaluation. The meanings of the judgment matrix elements are shown in Table 1.

$$
\begin{gathered}
R=\left|\begin{array}{ccc}
O_{11} & \cdots & O_{1 n} \\
\vdots & \vdots & \vdots \\
O_{n 1} & \cdots & O_{n n}
\end{array}\right|=\left[O_{i j}\right]_{n \times n} \\
i, j=1,2, \cdots, n \quad(7)
\end{gathered}
$$

$\mathrm{O}_{\mathrm{ij}}$ is the element of the judgment matrix.

\subsubsection{Weight vector}

A feature vector corresponding to the largest eigenvalue of the judgment matrix is regarded as the weight vector. Common methods of calculating the maximum eigenvalue and eigenvector are power method, sum method and root method. In this paper, the root method is selected to calculate the weight of the factors of the same layer in those of the upper layer, and this vector is called the weight vector. The product of the elements in the judgment matrix are calculated by rows and then extracted $\mathrm{n}$ roots ( $\mathrm{n}$ is the order of the matrix), followed by the normalization of the obtained vectors, that is:

$$
\tilde{\omega}=\sqrt[n]{\prod_{j=1}^{n} O_{i j}} \quad i, j=1,2, \cdots, n
$$

$$
\omega_{i}=\tilde{\omega}_{i} / \sum_{j=1}^{n} \tilde{\omega}_{j} i, j=1,2, \cdots, n
$$

\subsubsection{Consistency test}

Consistency test is an effective method to test the size of the judgment error caused by the feature vector as the weight vector. The rationality of the eigenvector as the weight vector, that is, whether the consistency of the judgment matrix is within the allowable variation range, can be judged according to the value of the consistency judgment coefficient $\mathrm{C}_{\mathrm{R}}{ }^{[5]}$. When $\mathrm{C}_{\mathrm{R}}<0.1$, the consistency of the judgment matrix is within the allowable range, and its feature vector corresponding to the largest eigenvalue can be used as the weight vector; When $C_{R} \geq 0.1$, it is necessary to re-evaluate objectively the importance between the indicators, adjust the scale value in the judgment matrix, and redo the consistency test until $\mathrm{C}_{\mathrm{R}}<0.1$.

$$
\begin{gathered}
C_{I}=\frac{\lambda_{\max }-n}{n-1} \\
\lambda_{\max }=\frac{1}{n} \sum_{i=1}^{n} \frac{(\Re \omega)_{i}}{\omega_{i}} \\
C_{R}=\frac{C_{I}}{R_{I}}
\end{gathered}
$$

$C_{I}$ is the consistency index, and the larger the $C_{I}$ value, the worse the consistency of the judgment matrix; $\lambda_{\max }$ is the maximum eigenvalue of the judgment matrix; $R_{I}$ is the average consistency index, and its values depending on the order the judgment matrix are as shown in Table 2; $(\Re \omega)_{i}$ is the ith component of the vector $\Re \omega$. 
Table 1. Elements and element values of the 1-9 scale method

\begin{tabular}{|c|c|c|c|}
\hline $\begin{array}{l}\text { Scaling } \\
\mathrm{O}_{\mathrm{ij}}\end{array}$ & Relative degree & $\begin{array}{l}\text { Scaling } \\
\mathrm{O}_{\mathrm{ij}}\end{array}$ & Relative degree \\
\hline 1 & $\mathrm{O}_{\mathrm{i}}$ is as important as $\mathrm{O}_{\mathrm{j}}$ & 1 & $\mathrm{O}_{\mathrm{j}}$ is as important as $\mathrm{O}_{\mathrm{i}}$ \\
\hline 2 & $\begin{array}{l}\mathrm{O}_{\mathrm{i}} \text { is as important as } \mathrm{O}_{\mathrm{j}} \sim \text { slightly } \\
\text { important }\end{array}$ & $1 / 2$ & $\begin{array}{l}\mathrm{O}_{\mathrm{j}} \text { is as important as } \mathrm{O}_{\mathrm{i}} \sim \text { slightly } \\
\text { important }\end{array}$ \\
\hline 3 & $\mathrm{O}_{\mathrm{i}}$ is slightly more important than $\mathrm{O}_{\mathrm{j}}$ & $1 / 3$ & $\begin{array}{l}\mathrm{O}_{\mathrm{j}} \text { is slightly more important than } \\
\mathrm{O}_{\mathrm{i}}\end{array}$ \\
\hline 4 & $\begin{array}{l}\mathrm{O}_{\mathrm{i}} \text { is slightly more important than } \mathrm{O}_{\mathrm{j}} \sim \\
\text { more important }\end{array}$ & $1 / 4$ & $\begin{array}{l}\mathrm{O}_{\mathrm{j}} \text { is slightly more important than } \\
\mathrm{O}_{\mathrm{i}} \sim \text { more important }\end{array}$ \\
\hline 5 & $\mathrm{O}_{\mathrm{i}}$ is more important than $\mathrm{O}_{\mathrm{j}}$ & $1 / 5$ & $\mathrm{O}_{\mathrm{j}}$ is more important than $\mathrm{O}_{\mathrm{i}}$ \\
\hline 6 & $\begin{array}{l}\mathrm{O}_{\mathrm{i}} \text { is more important than } \mathrm{O}_{\mathrm{j}} \sim \text { very } \\
\text { important }\end{array}$ & $1 / 6$ & $\begin{array}{l}\mathrm{O}_{\mathrm{j}} \text { is more important than } \mathrm{O}_{\mathrm{i}} \sim \text { very } \\
\text { important }\end{array}$ \\
\hline 7 & $\mathrm{O}_{\mathrm{i}}$ is more important than $\mathrm{O}_{\mathrm{j}}$ & $1 / 7$ & $\mathrm{O}_{\mathrm{j}}$ is more important than $\mathrm{O}_{\mathrm{i}}$ \\
\hline 8 & $\begin{array}{l}\mathrm{O}_{\mathrm{i}} \text { is more important than } \mathrm{O}_{\mathrm{j}} \sim \\
\text { absolutely important }\end{array}$ & $1 / 8$ & $\begin{array}{l}\mathrm{O}_{\mathrm{j}} \text { is more important than } \mathrm{O}_{\mathrm{i}} \sim \\
\text { absolutely important }\end{array}$ \\
\hline 9 & $\mathrm{O}_{\mathrm{i}}$ is absolutely more important than $\mathrm{O}_{\mathrm{j}}$ & $1 / 9$ & $\begin{array}{l}\mathrm{O}_{\mathrm{j}} \text { is absolutely more important } \\
\text { than } \mathrm{O}_{\mathrm{i}}\end{array}$ \\
\hline
\end{tabular}

Table 2. Average random consistency indicator

\begin{tabular}{cc||cc||cc}
\hline $\begin{array}{c}\text { Matrix } \\
\text { order }\end{array}$ & $R_{I}$ & $\begin{array}{c}\text { Matrix } \\
\text { order }\end{array}$ & $R_{I}$ & $\begin{array}{c}\text { Matrix } \\
\text { order }\end{array}$ & $R_{I}$ \\
\hline 1 & 0.00 & 4 & 0.90 & 7 & 1.32 \\
2 & 0.00 & 5 & 1.21 & 8 & 1.41 \\
3 & 0.58 & 6 & 1.24 & 9 & 1.46 \\
\hline
\end{tabular}

\subsection{Risk classification}

The risk value of each bridge is judged. According to the distribution of risk value, literature research and expert consultation, the risks are divided into three levels, shown as in Table 3.

(1) Level 1: It is expected that the normal water supply by the water outlet will be interrupted (seriously affected) for more than 24 hours. The large amount of abandoned water will cause greater economic losses and affect the water quality and ecological environment of the backwater area.

2) Level 2: It is expected that the normal water supply by the water outlet will be interrupted (seriously affected) for less than 24 hours, and a certain amount of water will be abandoned and cause large economic losses.

(3) Level 3: It is not expected that the water supply by the water outlet will be interrupted, but the gates need to be adjusted to treat the site.

Table 3. Risk values of each level

\begin{tabular}{rccc}
\hline Risk level & Level I & Level II & Level III \\
\hline Risk value $(\mathrm{F})$ & $0.70 \leq F \leq 1.0$ & $0.45<F \leq 0.70$ & $0<F \leq 0.45$ \\
\hline
\end{tabular}

\section{Conclusion}

On the basis of the risk assessment system, the risks of the bridges along the line are evaluated and graded .Due to too much bridge information, the results of some bridge risk classification and related information are listed in Table 4.

Table 4. Risk grades of sudden pollution

\begin{tabular}{|c|c|c|c|c|c|}
\hline $\begin{array}{c}\text { Branch } \\
\text { office }\end{array}$ & $\begin{array}{c}\text { Management } \\
\text { office }\end{array}$ & Bridge name & $\begin{array}{c}\text { Stake } \\
\text { number }\end{array}$ & level & Chemicals \\
\hline $\begin{array}{c}\text { Head } \\
\text { branch }\end{array}$ & Dengzhou & $\begin{array}{c}\text { Wang jia southwest } \\
\text { highway bridge }\end{array}$ & K9+884.4 & I & $\begin{array}{c}\text { Gasoline, diesel, methanol, } \\
\text { ethanol, explosive and toxic } \\
\text { chemicals }\end{array}$ \\
\cline { 2 - 6 } & Dengzhou & $\begin{array}{c}\text { Zhuying northwest } \\
\text { highway bridge }\end{array}$ & K33+750 & I & $\begin{array}{l}\text { Gasoline, diesel, methanol, } \\
\text { ethanol, explosive and toxic } \\
\text { chemicals }\end{array}$ \\
\hline
\end{tabular}




\begin{tabular}{|c|c|c|c|c|c|}
\hline & Nanyang & $\begin{array}{l}\text { Manzi village northeast } \\
\text { cross - channel highway } \\
\text { bridge }\end{array}$ & $109+996$ & $\mathrm{I}$ & $\begin{array}{l}\text { Gasoline, diesel, explosive } \\
\text { and toxic chemicals }\end{array}$ \\
\hline & Fangcheng & $\begin{array}{l}\text { Ma gang north highway } \\
\text { bridge }\end{array}$ & $144+372$ & I & Oil and toxic chemicals \\
\hline \multirow{9}{*}{$\begin{array}{l}\text { Henan } \\
\text { branch }\end{array}$} & Jiaxian & Shilipu highway bridge & $\mathrm{K} 283+703.5$ & I & $\begin{array}{l}\text { Gasoline, diesel, benzene, } \\
\text { methanol, sodium hydroxide, } \\
\text { asphalt, anhydrous ammonia, } \\
\text { petroleum ether }\end{array}$ \\
\hline & Xinzheng & $\begin{array}{c}\text { Bei jing-Hong } \\
\text { kong-Macao expressway }\end{array}$ & $\mathrm{K} 384+128$ & I & Gasoline, diesel \\
\hline & Xinzheng & $\begin{array}{l}\text { Zheng xin road highway } \\
\text { bridge }\end{array}$ & $\mathrm{K} 376+335$ & $\mathrm{I}$ & $\begin{array}{l}\text { Gasoline, diesel, natural gas, } \\
\text { sulfuric acid }\end{array}$ \\
\hline & $\begin{array}{l}\text { Aviation port } \\
\text { area }\end{array}$ & Four port linkage bridge & $\mathrm{K} 411+886.49$ & I & $\begin{array}{l}\text { Methanol, sulfuric acid, } \\
\text { diesel oil, gasoline }\end{array}$ \\
\hline & $\begin{array}{l}\text { Aviation port } \\
\text { area }\end{array}$ & $\begin{array}{c}\text { Bei jing-Hong } \\
\text { kong-Macao expressway }\end{array}$ & $\mathrm{K} 412+640.71$ & I & $\begin{array}{l}\text { Methanol, sulfuric acid, } \\
\text { diesel oil, gasoline }\end{array}$ \\
\hline & Xingyang & Science avenue bridge & $456+725.47$ & $\mathrm{I}$ & diesel oil \\
\hline & Wenbo & $\begin{array}{l}\text { Ma zhuang southeast } \\
\text { cross - channel highway } \\
\text { bridge }\end{array}$ & $\mathrm{k} 493+700.51$ & $\mathrm{I}$ & Methanol, diesel, gasoline \\
\hline & Wenbo & $\begin{array}{l}\text { Qi cun northeast cross - } \\
\text { channel highway bridge }\end{array}$ & $\mathrm{k} 518+140.50$ & I & Methanol, diesel, gasoline \\
\hline & Hebi & Qibin road bridge & K665+116.38 & $\mathrm{I}$ & $\begin{array}{l}\text { Gasoline, diesel, methanol, } \\
\text { propane, flammable liquids, } \\
\text { corrosives, liquefied } \\
\text { petroleum gas, compressed } \\
\text { natural gas, sulfuric acid }\end{array}$ \\
\hline \multirow{5}{*}{$\begin{array}{l}\text { Hebei } \\
\text { branch }\end{array}$} & Cixian & $\begin{array}{l}\text { Jiang wu cheng north } \\
\text { bridge }\end{array}$ & $3+490$ & $\mathrm{I}$ & $\begin{array}{l}\text { Methanol, sulfuric acid, } \\
\text { diesel, gasoline }\end{array}$ \\
\hline & Cixian & $\begin{array}{c}\text { Qinglan expressway } \\
\text { bridge }\end{array}$ & $25+170$ & I & $\begin{array}{l}\text { Methanol, sulfuric acid, } \\
\text { diesel, gasoline }\end{array}$ \\
\hline & Handan & Xue Zhuang bridge & $51+737$ & $\mathrm{I}$ & Gasoline, natural gas \\
\hline & Shijiazhuang & Longquan bridge & $225+640$ & $\mathrm{I}$ & Oil \\
\hline & Tangxian & Shannan Zhuang bridge & $332+420$ & $\mathrm{I}$ & $\begin{array}{l}\text { Inflammable, explosive and } \\
\text { corrosion products }\end{array}$ \\
\hline \multirow{3}{*}{$\begin{array}{l}\text { Beijing } \\
\text { branch }\end{array}$} & Yixian & $\begin{array}{l}\text { Zhangshi highway } \\
\text { bridge }\end{array}$ & $183+150.8$ & $\mathrm{I}$ & Oil \\
\hline & Laizhuo & $\begin{array}{l}\text { Zhangye highway } \\
\text { bridge }\end{array}$ & $215+709$ & II & $\begin{array}{l}\text { Inflammable chemicals and } \\
\text { dust }\end{array}$ \\
\hline & Laizhuo & $\begin{array}{l}\text { Jingkun expressway } \\
\text { bridge }\end{array}$ & $219+069$ & II & Inflammable chemicals \\
\hline $\begin{array}{l}\text { Tianjin } \\
\text { branch }\end{array}$ & Xiheisahan & Rongwu highway bridge & $1119+391$ & II & $\begin{array}{l}\text { Gasoline, diesel, benzene, } \\
\text { methanol, sodium hydroxide, } \\
\text { asphalt, anhydrous ammonia, } \\
\text { petroleum ether, others }\end{array}$ \\
\hline
\end{tabular}

Note: The Stake numbers of the Hebei branch and the Beijing branch are based on the starting points of the first management offices of the branch offices; The Henan Branch and the Tianjin Branch start with the head of the line. Same as Table 5.

According to the results of risk assessment, the proportion of bridge risks at level one and level two is small, while the proportion of bridges at level three is relatively large. Precautions should be taken in the dense area of the bridges at level one and level two. The key prevention areas are displayed in Table 5. Geographically, Henan has the largest number of bridges, and its proportion of bridges at all levels is larger than those of other provinces and cities. Therefore, it should take a high degree of prevention for key prevention areas in Henan. The classification status of local bridges is presented in Figure 4, and the classification status of each branch bridges is shown in Figure 5. 


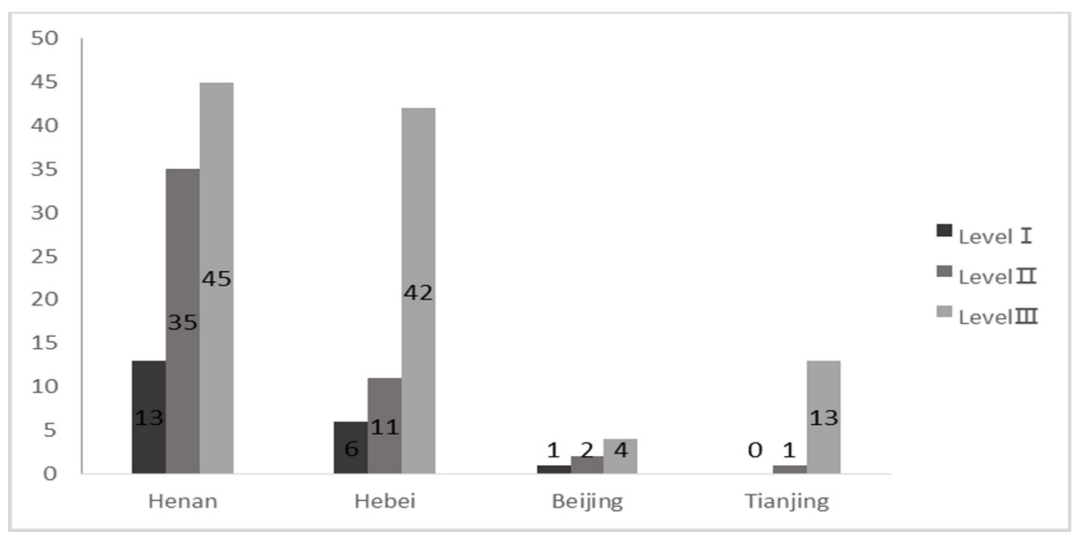

Figure 4. Bridge classification status map for each location

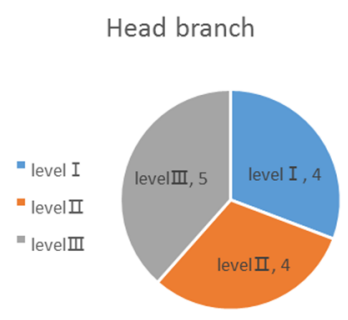

Henan branch

Hebei branch
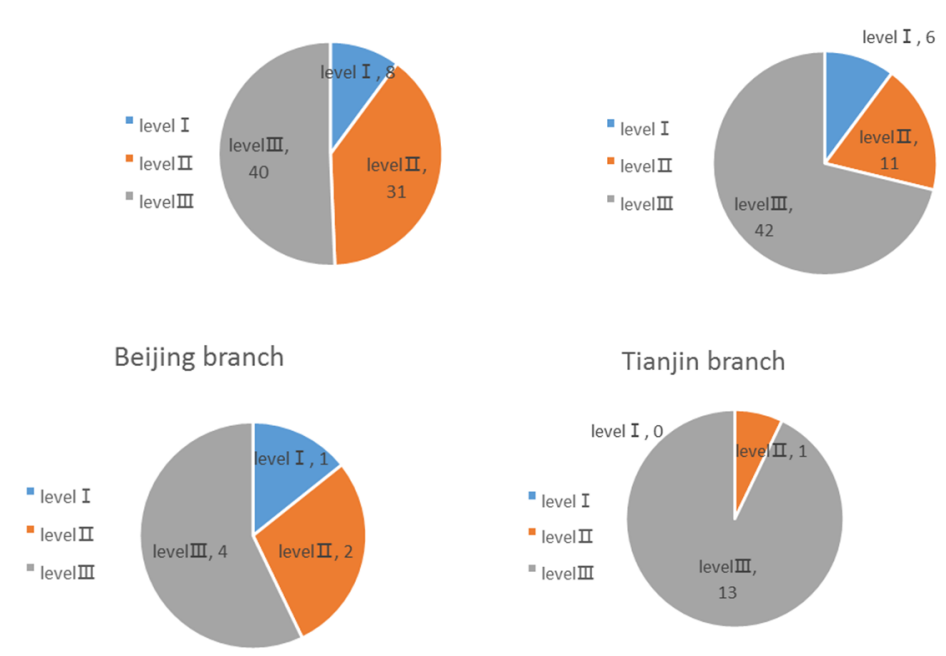

Figure 5. Classification status of each branch office

Table 5. Key prevention areas

\begin{tabular}{|c|c|c|}
\hline Branch office & Stake number & Prevention area \\
\hline \multirow{3}{*}{ Henan branch } & $\mathrm{K} 9+884.4 \sim 144+372$ & $\begin{array}{c}\text { Wangjia southwest highway bridge } \sim \text { Magang north } \\
\text { highway bridge }\end{array}$ \\
\hline & $\mathrm{k} 333+542.37 \sim \mathrm{K} 412+640.71$ & $\begin{array}{l}\text { Zhangnan highway bridge } \sim \text { Beijing-Hong } \\
\text { Kong-Macao expressway bridge }\end{array}$ \\
\hline & $\mathrm{K} 665+116.38 \sim \mathrm{k} 718+672.2$ & $\begin{array}{l}\text { Qibin avenue highway bridge } \sim \text { Bei Tuwang highway } \\
\text { bridge }\end{array}$ \\
\hline \multirow[t]{2}{*}{ Hebei branch } & $3+490 \sim 59+323$ & $\begin{array}{c}\text { Jiang Wucheng north bridge } \sim \text { Qinglan expressway } \\
\text { bridge }\end{array}$ \\
\hline & $225+640 \sim 344+285$ & Longquan bridge $\sim$ Baoyu expressway bridge \\
\hline \multirow{2}{*}{$\begin{array}{l}\text { Beijing branch } \\
\text { Tianjin branch }\end{array}$} & $183+150.800 \sim 219+069$ & Zhangshi highway bridge $\sim$ Jingkun expressway \\
\hline & $1119+169 \sim 1120+621$ & Zaoyuan bridge $\sim \mathrm{Xi}$ Heishan highway bridge \\
\hline
\end{tabular}

In order to detail the prevention, after comprehensively considering the risk assessment results and the key prevention areas, special consideration should be given to the bridges that are closer to the water outlets and the ones that are farther away from the backwater gates. Considering the patrolling interval of patrollers along the line, the pollution may not be discovered in the first time. The flow velocity of the main canal along the line is fast, and the pollutants migrate and spread quite rapidly, so the bridges closer to the water outlets should be given certain emergency prevention and frequent inspection tours. For the bridges far from the backwater gates, emergency material reserves should be made in the middle route. According to the formula (3), considering that after the patrolling time, the pollution occurrence time is 60 minutes, the pollutant transport distance is calculated to be 2160 meters. Bridges within 2160 meters from the backwater gates and water outlets should be inspected and monitored emphatically, to avoid missing the optimal backwater time and affecting the water supply by the water outlets. Among them, the Dongzhuang west highway bridge, and the Zhengzhou southwest expressway bridge, etc., which are closer to the water 
outlet, need to be monitored intensively. Emergency material reserves need to make along the way for the Guandian north road bridge, and the Provincial road 314 South-to-North Water Diversion bridge, etc., which are closer to the backwater gates. The conditions of some bridges, water outlets and backwater gates can be seen in Table 6.

Table 6. Conditions of Bridges, water outlets and backwater gates

\begin{tabular}{|c|c|c|}
\hline Name & Stake number & Distance (m) \\
\hline Xu Pingnan expressway cross-channel highway bridge & K193+879 & \multirow{2}{*}{636} \\
\hline Xinzhuang water inlet & $195+477$ & \\
\hline Guandian north road bridge & $\mathrm{k} 241+084$ & \multirow{2}{*}{626} \\
\hline Shahe riverbackwater gate & $241+710$ & \\
\hline Manliu northeast highway bridge & $\mathrm{k} 257+510$ & \multirow{2}{*}{1517} \\
\hline Mazhuang water inlet & $259+027$ & \\
\hline 107 national highway no. 1 highway Bridge & $\mathrm{K} 374+322$ & \multirow{2}{*}{975} \\
\hline Li Wei water intlet & $375+297$ & \\
\hline Bohai road highway bridge & $\mathrm{K} 440+224.68$ & \multirow{2}{*}{2000.68} \\
\hline Jiayu river backwater gate & $442+038$ & \\
\hline Zhengzhou southwest expressway bridge & K453+897 & \multirow{2}{*}{258} \\
\hline Qian Jiangzhai water diversion & $454+155$ & \\
\hline Provincial road 314 South-to-North Water Diversion bridge & $\mathrm{k} 478+027.55$ & \multirow{2}{*}{878.58} \\
\hline Yellow river backwater gate & $478+906.13$ & \\
\hline Zheng Jiaojin highway bridge & $\mathrm{K} 523+240$ & \multirow{2}{*}{957} \\
\hline Fucheng water inlet & $524+197$ & \\
\hline Dapushui north highway bridge & K607+447.049 & \multirow{2}{*}{1569.951} \\
\hline Mengfen river backwater gate & $609+017$ & \\
\hline Yangzhuang north highway bridge & K647+125.02 & \multirow{2}{*}{1162.98} \\
\hline Yuanzhuang water inlet & $648+288$ & \\
\hline Xinxiang tunuxi highway bridge & K657+457.64 & \multirow{2}{*}{1267.36} \\
\hline Sanlitun water inlet & $658+725$ & \\
\hline Dongzhuang west highway bridge & $\mathrm{k} 686+456.03$ & \multirow{2}{*}{39.97} \\
\hline Dongzhuang water inlet & $686+496$ & \\
\hline Civilization avenue highway bridge & $\mathrm{K} 711+035.2$ & \multirow{2}{*}{1830.8} \\
\hline Nanliu temple water inlet & $712+866$ & \\
\hline
\end{tabular}

8. A h.Gao,M y.Wang,H f.Wang, Journal of University of Chinese Academy of Sciences 30,763(2013)

\section{Acknowledgements}

This paper was supported by the Major Science and Technology Program for Water Pollution Control and Treatment (2017ZX07108-001).

\section{References}

1. Y y.Shi, China water resources 13,14 (2017)

2. W m.Tian, Water sciences and engineering technology s1,32 (2006)

3. H d.Wang, F.Wang, Journal of Beijing normal university(Natural Science)3,410 (1995)

4. J z.He,J.Li, Journal of waterway and harbor 27,269 (2006)

5. D.Yang,H.Zhang,X k.Guan, Water resources and power 12,182 (2013)

6. G h.Tang, X b.Zeng, Journal of Hebei university of Economics and Business 4 ,60(1997)

7. Y.Long,Doctoral dissertation (2017)
9. Q.Wang, $\mathrm{N} \mathrm{Xu}, \mathrm{J}$ q.Gao, Haihe water resources 6,19(2017)

10. T Li, Doctoral dissertation (2014)

11. K.Zhou,W.Wu,W j.Yao, Journal of transport science and engineering $\mathbf{1}, 79(2015)$

12. L q.Huang, J.Yang, $\mathrm{C}$ y.Wang,Water resources and hydropower engineering 45,23(2014)

13. Y.Liu,J m.Liu,J s.Zhang,Water resources and hydropower engineering36,114(2005)

14. H.Wang, $H$ z.Z, $X$ h.Lei, Journal of sichuan university (engineering science edition) 48,1(2016)

15. X g.Han, $\mathrm{T}$ 1.Huang,Water resources protection 26,84(2010)

16. B e.Huang, Doctoral dissertation (2012)

17. Zhao, X. M, Chemosphere 194, 107(2017)

18. Foufou. A, Djorfi. S, Haied. N, Energy Procedia 119, 393(2017)

19. Y.Z, Y.H, D.H, Environ.Pollut 239,223(2018)

20. J.L, L.Guo, Z L.Du, Advanced Materials Research 
1010,357 (2014) 